\title{
Ultraviolet-visible Spectrophotometric Method for Estimation of Gliclazide in Presence of Excipients Interacting in UV-visible Region
}

\author{
Neelkant Prasad ${ }^{1, *}$, Aditya Sharma ${ }^{2}$ \\ 'S G T College of Pharmacy, S G T University, Gurugram-Badli Road, Budhera, Gurugram, Haryana, INDIA. \\ ${ }^{2}$ School of Pharmaceutical Sciences, IFTM University, Delhi Road, Lodhipur Rajput, Moradabad, Uttar Pradesh, INDIA.
}

\begin{abstract}
A simple and sensitive ultraviolet spectrophotometric method for quantitative estimation of a model API gliclazide in presence of excipients is described to avoid false estimation due to presence of soluble or insoluble impurity. UV detection was performed at $226 \mathrm{~nm}, 221 \mathrm{~nm}$ and $231 \mathrm{~nm}$ and the calibration curve was prepared between the resultant of absorbance at these three wavelengths according to the equation [226 nm $(221 \mathrm{~nm}+231 \mathrm{~nm}) / 2$ ] and the concentration of gliclazide. The calibration curve was found to be linear over concentration range tested $(04-28 \mu \mathrm{g} / \mathrm{ml})$ having limit of detection of $0.45 \mu \mathrm{g} / \mathrm{ml}$ and limit of quantification $1.36 \mu \mathrm{g} / \mathrm{ml}$. Percent relative standard deviations, representing precision, for pure as well as impure solutions were found to be within acceptable limits i.e. always less than 1.99 and 2.00 respectively for pure and impure solution. Mean percent recovery of $99.21 \%-102.04 \%$ and $102.06 \%-103.74 \%$ for pure and impure solution respectively indicates that the developed method is accurate. Conclusively, the developed method can be effectively applied for the estimation of gliclazide in pure as well as impure solutions and it was seen that the analyte in both types of solutions can be detected from same calibration curve accurately and precisely. Key words: Pure, Impure, Excipients, UV spectrophotometric method, Gliclazide.
\end{abstract}

\section{INTRODUCTION}

The samples of dissolution of various dosage forms like tablets, capsules, solid dispersions, gels etc. and samples from solubility studies contain dissolved or undissolved substances that might interact with quantitative estimation of substance of interest until and unless separated.

Separation of undissolved impurity can be achieved by filtration ${ }^{1}$ and/ or centrifugation ${ }^{2}$ while dissolved interacting substance can be separated by chromatographic methods like HPLC. ${ }^{3}$ All these separation methods require special technique/s and instrument/s involved with them. These cause multiple increases in the costs as well as the time duration of evaluation.

Further, filtration may cause adsorption of analyte drug substance of interest onto the filter medium., ${ }^{4,5}$ HPLC requires use of various organic solvents and their combination to achieve complete separation of the interacting substances. Moreover, all these techniques result in consumption of power and energy. Dissolved impurities are separated by chromatographic columns and the process is tedious, costly and time consuming.

Derivative spectrophotometry, bichromatic methods and difference spectrophotometry can also be applied for elimination of background light absorption but all these methods are more or less complex. ${ }^{6}$ Also, derivative spectrophotometry results in more complex spectrum. ${ }^{7}$

Different analytical methods including UV spectrophotometry ${ }^{4}$, gas chromatography ${ }^{5}$, HPLC, 6,7 Evaporative Light Scattering Detection, ${ }^{8}$ Charged Aerosol Detection ${ }^{8}$
Submission Date: 28-06-2019; Revision Date: 05-11-2019; Accepted Date: 30-04-2020

DOI: 10.5530/ijper.54.2s.91 Correspondence: Dr. Neelkant Prasad Associate Professor, College of Pharmacy, S G T University, Gurugram-Badli Road, Budhera, Gurugram-122505, Haryana, INDIA.

Phone: +91 9027169402 E-mail: prasadneelkant@ gmail.com

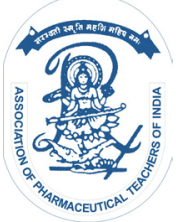

www.ijper.org 
have been reported for determination of gliclazide. Some reported analytical methods involve time consuming and laborious extraction steps and lengthy retention time. ${ }^{5,6}$ Various procedures for aqueous sample assessment are also available $e^{7-12}$ but none of these methods can be used for estimation of dissolution samples containing dissolved as well as undissolved impurities, interacting in UV-visible region, without separation of impurities i.e. separation of impurities (dissolved and undissolved) is required for estimation by these methods because the impurities interacting in the UV-visible region result in false estimation of the analyte.

In the method by Phalke P. N. et al. $1997^{13}$ glipizide has derivatized by complexation with acridine yellow followed by extraction of the resulting complex in chloroform and then quantitative evaluation. Firstly, this method is time consuming and secondly, presence of impurity might affect the complexation reaction. In a further study by B. Henry et al. 2009, ${ }^{14}$ molar extinction coefficient of the drug was estimated. This method also requires a solution having no such impurities interfering in the UV-visible region. Likewise, methods from other researchers like Sköld, C. et al. $2006^{15}$ and Vargas, F. et al. $2000^{16}$ are also not found to be suitable due to various similar reasons for estimation of dissolution samples directly along with interfering impurities present in it.

Dissolved impurities are separated by chromatographic columns and the process is tedious, costly and time consuming. On the other hand, undissolved impurities are separated either by filtration or by centrifugation which are further tedious, costly and time consuming. Also the analyte of interest might adsorb onto the filter medium. Further, sometimes a centrifuge or high speed cooling ultracentrifuge is required for separation that is more power consuming.

An easy to calculate and simple ultraviolet spectrophotometric method is described here to eliminate the effect of dissolved and/or undissolved interacting substances. The developed method can be magnificently applied to quantitatively estimate the drug of interest in presence of dissolved and/ or undissolved interacting substances/ impurities during dissolution as well as for determining drug content of the formulations without separation of impurities. The same method has been found to be applicable to estimate the pure drug also. In this method, the impurities has been added from outside is in the form of common excipients in the appropriate ratio such that they comply with the model quantity of excipients.

\section{MATERIALS AND METHODS}

All the reagent grade chemicals were used. Gliclazide was gentle gifted by Alkem Laboratories Limited, Taloja, Raigarh, Maharashtra, India. Acetonitrile (ACN), potassiumdihydrogen-orthophosphate and sodium hydroxide were procured from Loba Chemie Pvt. Ltd., Mumbai, India. A Shimadzu Pharmspec UV 1800 ultraviolet-visible spectrophotometer was used.

\section{Preparation of calibration curve}

A stock solution A of concentration $1000 \mu \mathrm{g} / \mathrm{ml}$ was prepared by dissolving $50 \mathrm{mg}$ gliclazide in 1:3 Phosphate buffer $\mathrm{pH}$ 7.4:ACN in a $50.0 \mathrm{ml}$ capacity volumetric flask and making the final volume up to the mark with the same solvent.

A working stock solution B of $50 \mu \mathrm{g} / \mathrm{ml}$ was prepared by diluting $12.5 \mathrm{ml}$ of the stock solution A up to mark in a $250 \mathrm{ml}$ capacity volumetric flask with the phosphate buffer $\mathrm{pH} 7.4 \pm 0.1$.

A working impure stock solution C of $50 \mu \mathrm{g} / \mathrm{ml}$ concentration was prepared by adding most common formulation ingredients like diluents (lactose), binder (starch), humectants (glycerol), color (FDA approved dyes and lakes), flavor (vanilla), sweetener (mannitol), emulsifier (lecithin), preservatives and antioxidants (methyl paraben), in their usual strengths in the formulation, without drug to the working stock solution B (50 $\mu \mathrm{g} / \mathrm{ml}$ ), previously prepared, in a $100 \mathrm{ml}$ capacity volumetric flask. The solution was then sonicated for $10 \mathrm{~min}$ and made the volume up to mark with the same stock solution.

Various aliquots of working stock solutions B and C were transferred to $10 \mathrm{ml}$ volumetric flasks so as to prepare various alternate pure and impure working standard dilutions of $4,6,8,12,16,20,24,28,32,36$, 38 and $40 \mu \mathrm{g} / \mathrm{ml}$ and volume was made up to mark with phosphate buffer $\mathrm{pH} 7.4 \pm 0.1$. The calibration curve was then prepared in the range of $4-28 \mu \mathrm{g} / \mathrm{ml}$ against clear blank by taking the absorbances of the standard dilutions at three wavelengths i.e. wavelength of maximum absorption $\lambda_{\max }(226 \mathrm{~nm})$ and at two wavelengths equidistant on either side of $\lambda_{\max }$ i.e. $221 \mathrm{~nm}$ and $231 \mathrm{~nm}$, taking the average of the later two, subtracting the average from the absorbance at $\lambda_{\text {max }}(226$ $\mathrm{nm})$ and plotting resultant against concentration.

The curve was prepared in the concentration range of $4-28 \mu \mathrm{g} / \mathrm{ml}$ only because the linearity was being followed by the samples in the concentration range of $4-28 \mu \mathrm{g} / \mathrm{ml}$ only and not by the samples having concentration above $28 \mu \mathrm{g} / \mathrm{ml}$. 


\section{Validation}

\section{Specificity}

Pure as well as impure standard solutions of gliclazide $(11.2,14$ and $16.8 \mu \mathrm{g} / \mathrm{ml})$ were prepared separately in phosphate buffer $\mathrm{pH} 7.4 \pm 0.1$. All solutions were scanned between 400 to $200 \mathrm{~nm}$ and checked for any difference in corrected absorbance of pure and impure solutions at wavelengths of study i.e. $221 \mathrm{~nm}, 226 \mathrm{~nm}$ and $231 \mathrm{~nm}$. The spectra of the pure and impure solutions of gliclazide were also observed for any change in wavelength of maximum absorbance. ${ }^{17}$

\section{Linearity}

Linearity of the calibration curve prepared was determined using linear regression analysis ${ }^{17}$ as well as test of residuals by plotting residual amount versus variable (concentration predicted) curve. $^{18}$

\section{Precision}

Repeatability was determined by analyzing different levels of drug concentrations i.e. $11.2,14$ and $16.8 \mu \mathrm{g} / \mathrm{ml}$ from independent stock solutions (with and without impurity) $(n=6)$. Inter-day and intra-day variations in estimation were determined to assess intermediate precision of the developed method. Different levels $80 \%, 100 \%$ and $120 \%$ of midpoint of the linear range drug concentrations (with and without turbidity) in triplicates were analyzed three times in a day for intra-day variation. The same method was followed for three different days to study inter-day variation. The precision was determined as relative standard deviation. ${ }^{17}$

\section{Accuracy}

The accuracy studies were performed at three levels i.e. $80 \%, 100 \%$ and $120 \%$ of midpoint of the linear range drug concentrations by adding known amounts of the drug to a known concentration $(50 \%$ of the midpoint of the linear range concentration) of the standard and analyzing the percent drug content (standard addition method) ${ }^{17}$

\section{Limit of detection and limit of quantification}

The limit of detection (LOD) and the limit of quantification (LOQ) of the drugs by proposed method were determined using calibration standards. The LOD and LOQ were calculated as per the following equations, (ICH Guidelines Q2 (R1), 2005). ${ }^{17}$

$$
\mathrm{LOD}=3.3\left(\frac{\mathrm{SD}_{\text {Intercept }}}{\text { Slope }}\right)
$$

$$
\mathrm{LOD}=10\left(\frac{\mathrm{SD}_{\text {Intercept }}}{\text { Slope }}\right)
$$

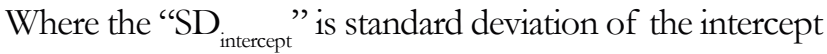
of the regression line and the "Slope" is the slope of the prepared calibration curve.

\section{RESULTS AND DISCUSSION}

The UV spectra of the prepared pure and impure standard solutions of gliclazide were recorded between $400 \mathrm{~nm}$ and $200 \mathrm{~nm}$.

Both the spectra exhibited a prominent peak at $226 \mathrm{~nm}$ (Figure 1) and it was reflected for further studies as $\lambda_{\max }$. Two other wavelengths of measurements used were 221 $\mathrm{nm}$ and $231 \mathrm{~nm}$ (i.e. equidistant on either side of $\lambda_{\text {max }}$ ) and the curve was prepared by plotting corrected absorbance i.e. $\left[A_{226}-\left(A_{221}+A_{231}\right) / 2\right]$ on Y-axis against concentration on $\mathrm{X}$-axis (Figure 2 ).

The Beer's law was obeyed and validated from $4-28 \mu \mathrm{g} / \mathrm{ml}$. The linear regression equation was found to be $\mathrm{A}=0.003 \mathrm{C}+0.003$, where $\mathrm{A}$ is the absorbance and $\mathrm{C}$ is the concentration, with correlation coefficient of 0.999 (Table 1). The linearity was also proved through test for residuals by plotting residual amount versus variable curve (concentration predicted) curve. A random pattern indicates the linearity (Table 2 and Figure 3).

The method was validated through specificity, repeatability, precision and accuracy according to ICH Guidelines Q2 (R1), 2005 recommendations. ${ }^{17}$ The results are presented in Tables 3-7.

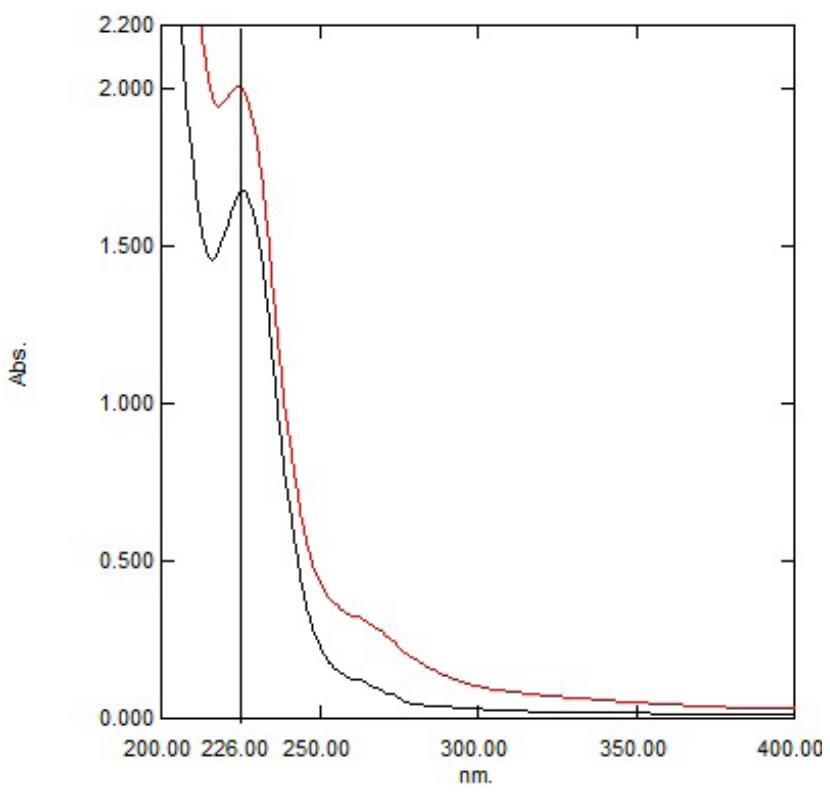

Figure 1: Overlain UV spectra of gliclazide in phosphate buffer pH 7.4 (pure and impure). 


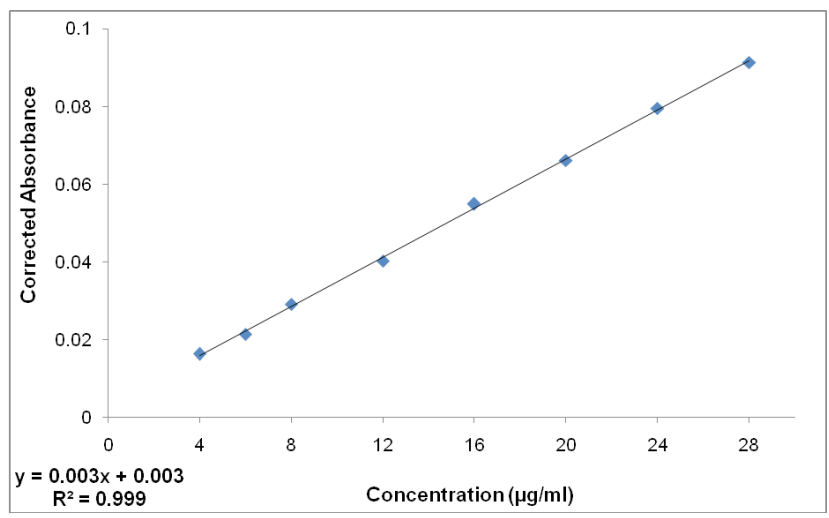

Figure 2: Calibration curve of gliclazide in phosphate buffer pH 7.4.

\begin{tabular}{|c|c|c|}
\hline \multicolumn{3}{|c|}{ Table 2: Test for residuals. } \\
\hline $\begin{array}{c}\text { Predicted } \\
\text { Concentration } \\
(\mu \mathrm{g} / \mathrm{ml})\end{array}$ & $\begin{array}{c}\text { Observed } \\
\text { Concentration } \\
(\mu \mathrm{g} / \mathrm{ml})\end{array}$ & $\begin{array}{c}\text { Residual Amount } \\
(\mu \mathrm{g} / \mathrm{ml})\end{array}$ \\
\hline 1 & 1.202627 & 0.202627 \\
\hline 1.5 & 1.571607 & 0.071607 \\
\hline 2 & 2.057849 & 0.057849 \\
\hline 3 & 2.9803 & -0.0197 \\
\hline 4 & 4.010632 & 0.010632 \\
\hline 6 & 5.852408 & -0.14759 \\
\hline 8 & 7.777048 & -0.22295 \\
\hline 12 & 11.99312 & -0.00688 \\
\hline 16 & 15.77236 & -0.22764 \\
\hline 20 & 20.32395 & 0.323952 \\
\hline
\end{tabular}

\section{Table 1: Regression parameters for calibration curve of Gliclazide.}

\begin{tabular}{|c|c|c|}
\hline No. & Parameter & Value \\
\hline 1 & Analytical wavelengths $(\mathrm{nm})$ & 221,226 and 231 \\
\hline 2 & $\begin{array}{c}\text { Equation for corrected } \\
\text { absorbance }\end{array}$ & $\left.\mathrm{A}_{226}-\left(\mathrm{A}_{221}+\mathrm{A}_{231}\right) / 2\right]$ \\
\hline 3 & Linearity range $(\mathrm{mg} / \mathrm{ml})$ & $04-28$ \\
\hline 4 & Regression equation $(\mathrm{A}=\mathrm{aC}+\mathrm{b})^{\mathrm{a}}$ & $\mathrm{A}=0.003 \mathrm{C}+0.003$ \\
& $\begin{array}{c}\text { Slope }(\mathrm{a}) \\
\text { Intercept }(\mathrm{b})\end{array}$ & 0.003 \\
\hline 5 & SD of intercept $(n=6)$ & $4.08 \times 10^{-4}$ \\
\hline 6 & Correlation coefficient & 0.999 \\
\hline
\end{tabular}

${ }^{\mathrm{a}} \mathrm{A}=$ Absorbance and $\mathrm{C}=$ Concentration

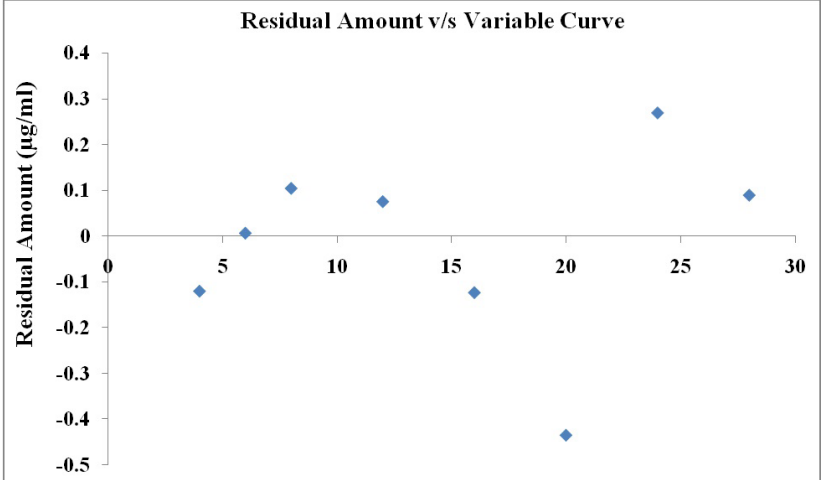

Variable (Concentration Predicted, $\mu \mathrm{g} / \mathrm{ml})$

Figure 3: Residual amount v/s variable (concentration predicted) curve.

Table 3: Specificity studies for the developed analytical method for Gliclazide.

\begin{tabular}{|c|c|c|c|c|}
\hline \multirow{2}{*}{$\begin{array}{c}\text { Concentration } \\
\text { taken }(\mu \mathrm{g} / \mathrm{ml})\end{array}$} & \multicolumn{2}{|c|}{ Corrected absorbance* for } & $\begin{array}{c}\text { Corrected absorbance } \\
\text { difference }\left(\mathbf{A}_{\mathrm{c}}-\mathbf{A}_{\mathrm{t}}\right)\end{array}$ & $\begin{array}{c}\text { \%Corrected absorbance } \\
\text { difference }\left(\mathbf{w} \text {. r. } \mathbf{t} \text {. } \mathbf{A}_{\mathrm{c}}\right)\end{array}$ \\
\cline { 2 - 3 } & Pure solution $\left(\mathbf{A}_{\mathrm{c}}\right)$ & Impure solution $\left.\mathbf{A}_{\mathrm{t}}\right)$ & 0.000 & 0.00 \\
\hline 11.2 & $0.037 \pm 0.001$ & $0.037 \pm 0.001$ & -0.001 & 1.82 \\
\hline 14 & $0.046 \pm 0.001$ & $0.047 \pm 0.001$ & 0.001 & 1.88 \\
\hline
\end{tabular}

*Mean \pm SD of 6 replicate determinations, "Solution of gliclazide with added excipients

The method was found to be specific as indicated The low values of RSD $(<1.99$ and $<2.00$ for pure and by always less than $1.88 \%$ difference in corrected impure solution respectively, Tables 4-6) indicated that the developed method was precise.

absorbance at 11.2, 14 and $16.8 \mu \mathrm{g} / \mathrm{ml}$ pure and impure The accuracy was studied by recovery studies. The percent recovery of the added known amounts of the drug to solutions of gliclazide (Table 3).

a known concentration of the sample was always found 
Table 4: Repeatability studies for the developed analytical method for Gliclazide.

\begin{tabular}{|c|c|c|c|c|c|c|c|c|c|}
\hline \multirow[t]{3}{*}{ Solution } & \multicolumn{8}{|c|}{ Concentration of drug solution $(\mu \mathrm{g} / \mathrm{ml})$} & \multirow[t]{3}{*}{ RSD } \\
\hline & \multirow[t]{2}{*}{ Prepared } & \multicolumn{7}{|c|}{ Found } & \\
\hline & & 1 & 2 & 3 & 4 & 5 & 6 & Mean* & \\
\hline Pure Solution & 14 & 14.33 & 14.00 & 14.33 & 14.33 & 14.33 & 14.00 & $14.22 \pm 0.17$ & 1.21 \\
\hline Impure" Solution & 14 & 14.67 & 14.33 & 14.67 & 14.33 & 14.33 & 14.67 & $14.50 \pm 0.18$ & 1.26 \\
\hline
\end{tabular}

*Mean \pm SD, "Solution of gliclazide with added excipients, RSD- Relative Standard Deviation

\begin{tabular}{|c|c|c|c|c|c|c|}
\hline \multirow[t]{3}{*}{ Solution } & \multicolumn{5}{|c|}{ Concentration of drug solution $(\mu \mathrm{g} / \mathrm{ml})$} & \multirow[t]{3}{*}{ RSD } \\
\hline & \multirow[t]{2}{*}{ Taken } & \multicolumn{4}{|c|}{ Found } & \\
\hline & & $t 1^{* *}$ & $\mathbf{t 2}^{* *}$ & $\mathbf{t} 3^{* *}$ & Mean* & \\
\hline \multirow{3}{*}{ Pure Solution } & 11.2 & $11.22 \pm 0.17$ & $11.11 \pm 0.17$ & $11.44 \pm 0.17$ & $11.26 \pm 0.21$ & 1.91 \\
\hline & 14.0 & $14.22 \pm 0.17$ & $14.56 \pm 0.17$ & $14.50 \pm 0.18$ & $14.43 \pm 0.22$ & 1.55 \\
\hline & 16.8 & $16.72 \pm 0.14$ & $16.89 \pm 0.17$ & $16.89 \pm 0.17$ & $16.83 \pm 0.17$ & 1.01 \\
\hline \multirow{3}{*}{$\begin{array}{l}\text { Impure\# } \\
\text { Solution }\end{array}$} & 11.2 & $11.44 \pm 0.17$ & $10.78 \pm 0.17$ & $11.17 \pm 0.18$ & $11.13 \pm 0.33$ & 1.99 \\
\hline & 14.0 & $14.50 \pm 0.18$ & $14.50 \pm 0.18$ & $14.17 \pm 0.18$ & $14.39 \pm 0.23$ & 1.64 \\
\hline & 16.8 & $17.06 \pm 0.25$ & $16.83 \pm 0.18$ & $16.78 \pm 0.17$ & $16.89 \pm 0.23$ & 1.35 \\
\hline
\end{tabular}

*Mean \pm SD of 18 determinations ( 6 replicate determinations every time for 3 points of time in a day), ** Mean \pm SD of 6 replicate determinations, ${ }^{*}$ Solution of gliclazide with added excipients, RSD- Relative Standard Deviation

\begin{tabular}{|c|c|c|c|c|c|c|}
\hline \multirow[t]{3}{*}{ Solution } & \multicolumn{5}{|c|}{ Concentration of drug solution $(\mu \mathrm{g} / \mathrm{ml})$} & \multirow[t]{3}{*}{ RSL } \\
\hline & \multirow[t]{2}{*}{ Taken } & \multicolumn{4}{|c|}{ Found } & \\
\hline & & Day $1^{* *}$ & Day $2^{* *}$ & Day $3^{* *}$ & Mean* & \\
\hline \multirow{3}{*}{ Pure Solution } & 11.2 & $11.22 \pm 0.17$ & $11.44 \pm 0.17$ & $10.78 \pm 0.17$ & $11.15 \pm 0.32$ & 1.99 \\
\hline & 14.0 & $14.22 \pm 0.17$ & $14.39 \pm 0.25$ & $13.72 \pm 0.14$ & $14.11 \pm 0.34$ & 1.98 \\
\hline & 16.8 & $16.72 \pm 0.14$ & $17.17 \pm 0.28$ & $16.83 \pm 0.18$ & $16.91 \pm 0.34$ & 1.62 \\
\hline \multirow{3}{*}{ Impure\# Solution } & 11.2 & $11.44 \pm 0.17$ & $11.56 \pm 0.17$ & $10.83 \pm 0.18$ & $11.28 \pm 0.36$ & 1.96 \\
\hline & 14.0 & $14.50 \pm 0.18$ & $14.44 \pm 0.17$ & $13.78 \pm 0.17$ & $14.24 \pm 0.37$ & 2.00 \\
\hline & 16.8 & $17.06 \pm 0.25$ & $17.22 \pm 0.17$ & $16.78 \pm 0.17$ & $17.02 \pm 0.27$ & 1.57 \\
\hline
\end{tabular}

*Mean \pm SD of 18 determinations ( 6 replicate determinations every time for 3 points of time in a day), **Mean \pm SD of 6 replicate determinations, " Solution of gliclazide with added excipients, RSD- Relative Standard Deviation.

\begin{tabular}{|c|c|c|c|c|c|}
\hline \multirow[t]{2}{*}{$C_{s}(\mu \mathrm{g} / \mathrm{ml})$} & \multirow[t]{2}{*}{$\mathrm{C}_{\mathrm{a}}(\mu \mathrm{g} / \mathrm{ml})$} & \multicolumn{2}{|c|}{ Pure solution } & \multicolumn{2}{|c|}{ Impure solution" } \\
\hline & & $C_{t}^{*}(\mu g / m l)$ & \%Recovery ${ }^{* \dagger}$ & $C_{t}^{*}(\mu g / m l)$ & $\%$ Recovery \\
\hline \multirow{3}{*}{7} & 4.2 & $10.94 \pm 0.14$ & $99.21 \pm 3.2$ & $11.06 \pm 0.14$ & $103.17 \pm 2.10$ \\
\hline & 7 & $13.78 \pm 0.17$ & $100.32 \pm 2.46$ & $13.89 \pm 0.17$ & $102.06 \pm 2.01$ \\
\hline & 9.8 & $16.78 \pm 0.17$ & $102.04 \pm 1.76$ & $16.89 \pm 0.17$ & $103.74 \pm 1.75$ \\
\hline
\end{tabular}

$\mathrm{C}_{\mathrm{s}}=$ Concentration of standard solution, $\mathrm{C}_{\mathrm{a}}=$ Concentration of sample solution added and $\mathrm{C}_{\mathrm{t}}=$ Total concentration found, ${ }^{+} \%$ Recovery= $\left[\left(\mathrm{C}_{\mathrm{t}}-\mathrm{C}_{\mathrm{s}}\right) / \mathrm{C}_{\mathrm{a}}\right] \times 100$, $*$ Mean $\pm S D$ of 6 replicate determinations, "Solution of gliclazide with added excipients 
to be $99.21 \%-102.04 \%$ for pure solution and $102.06 \%$ $103.74 \%$ for impure solution (Table 7).

The limit of detection (LOD) and limit of quantification (LOQ) of gliclazide by the proposed method were found to be 0.45 and $1.36 \mu \mathrm{g} / \mathrm{ml}$ respectively.

\section{CONCLUSION}

The proposed method has been proved to be simple, precise, rapid and reliable and was validated through the validation parameters as described in the ICH Q2 (R1) guideline $^{17}$ for specificity, linearity, LOD values, LOQ values, inter- and intra-day precision and accuracy which were obtained during the validation studies and were found to be within acceptable limits.

The method can be successfully employed for quantification of gliclazide in all types of pharmaceutical formulations and liquid samples with and without excipient impurities.

\section{ACKNOWLEDGEMENT}

Authors are thankful to the S G T College of Pharmacy, S G T University, Gurugram and School of Pharmaceutical Sciences, IFTM University, Moradabad for facilities and support to complete this work.

\section{CONFLICT OF INTEREST}

The authors declare no conflict of interest.

\section{ABBREVIATIONS}

UV: Ultraviolet; HPLC: High performance liquid chromatography; GLIP: Glipizide; ACN: Acetonitrile; LOD: Limit of detection; LOQ: Limit of quantification; $\mathrm{SD}_{\text {intercept }}$ : Standard deviation of intercept of the calibration curve; ICH: International conference on harmonization; SD: Standard deviation; RSD: Relative standard deviation.

\section{REFERENCES}

1. Nounou MM, El-Khordagui LK, Khalafallah NA, Khalil SA. In vitro release of hydrophilic and hydrophobic drugs from liposomal dispersions and gels. Acta Pharmaceutica. 2006;56(3):311-24.

2. Ramprasa MP, Anantharamaiah GM, Garber DW, Katre NV. Sustaineddelivery of an apolipoproteinE-peptidomimetic using multivesicular liposomes lowers serum cholesterol levels. Journal of Controlled Release. 2002;79(1-3):207-18.

3. Mumper RJ, Hoffman AS. The stabilization and release of hirudin from liposomes or lipid-assemblies coated with hydrophobically modified dextran. AAPS Pharm Sci Tech. 2000;1(1):20-9.

4. Adhikari L, Jagadev S, Sahoo S, Murthy PN, Mishra US. Developement and validation of UV-visible spectrophotometric method for simultaneous determination of pioglitazone hydrochloride, metformin hydrochloride and glipizide in its bulk and pharmaceutical dosage form. International Journal of ChemTech Research. 2012;4(1):625-30.

5. Gumieniczek A, Berecka A. Comparison of capillary electrophoresis and UV derivative spectrophotometry for determination of pioglitazone, glipizide and repaglinide. Annales Universitatis Mariae Curie-Sklodowska, Sectio DDD: Pharmacia. 2011;24(1):15-23.

6. Shaodong J, Lee WJ, Ee JW, Park JH, Kwon SW, Lee J. Comparison of ultraviolet detection, evaporative light scattering detection and charged aerosol detection methods for liquid-chromatographic determination of anti-diabetic drugs. Journal of Pharmaceutical and Biomedical Analysis. 2010;51(4):973-8.

7. Rathod DR, Dole MN, Sawant SD. Spectrophotometric determination of glipizide in bulk and tablet dosage form by absorption maxima, first order derivative spectroscopy and area under the curve. Asian Journal of Pharmaceutical and Clinical Research. 2012;5(Suppl 3):102-4.

8. Chungath TT, Reddy YP, Devanna N. Simultaneous spectrophotometric estimation of metformin hydrochloride and glipizide in tablet dosage forms. International Journal of Pharm Tech Research. 2011;3(4):2064-7.

9. Aruna A, Nancy K. Simultaneous estimation of metformin HCL and glipizide in solid dosage forms by ultraviolet spectrophotometry. Aruna Indian Drugs. 2000;37(11):533-6.

10. Shivakumar HN, Desai BG, Pandya S, Karki SS. Influence of $\beta$-cyclodextrin complexation on glipizide release from hydroxypropyl methylcellulose matrix tablets. PDA Journal of Pharmaceutical Science and Technology. 2007;61(6):472-91.

11. Verma RK, Garg S. Selection of excipients for extended release formulations of glipizide through drug-excipient compatibility testing. Journal of Pharmaceutical and Biomedical Analysis. 2005;38(4):633-44.

12. Radi AEM, Eissa SH. Voltammetric and spectrophotometric studies on the inclusion complex of glipizide with $\beta$-cyclodextrin. Eurasian Journal of Analytical Chemistry. 2011;6(1):13-21.

13. Phalke PN, Sherikar AV, Dhadke PM. Direct spectrophotometric analysis of glipizide and phenformin hydrochloride in pharmaceutical dosage forms. Indian Journal of Pharmaceutical Sciences. 1997;59(1):18-21.

14. Henry B, Foti C, Alsante K. Can light absorption and photostability data be used to assess the photosafety risks in patients for a new drug molecule?. Journal of Photochemistry and Photobiology B: Biology. 2009;96(1):57-62.

15. Sköld C, Winiwarter S, Wemevik J, Bergström F, Engström L, Allen R, et al. Presentation of a structurally diverse and commercially available drug data set for correlation and benchmarking studies. Journal of Medicinal Chemistry. 2006;49(23):6660-71.

16. Vargas $F$, Méndez $H$, Tropper E. Studies on the in vitro phototoxicity of the antidiabetes drug glipizide. In vitro and Molecular Toxicology: Journal of Basic and Applied Research. 2000;13(1):17-24.

17. $\mathrm{ICH}$ Guidelines Q2 (R1). Validation of analytical procedures: text and methodology. ICH harmonized tripartite guidelines. 2005;11.

18. Variations of linearity. 2013. [cited 2013.07.17]. Available from: URL: http:// people.duke.edu/ rnau/testing.htm 


\section{PICTORIAL ABSTRACT}

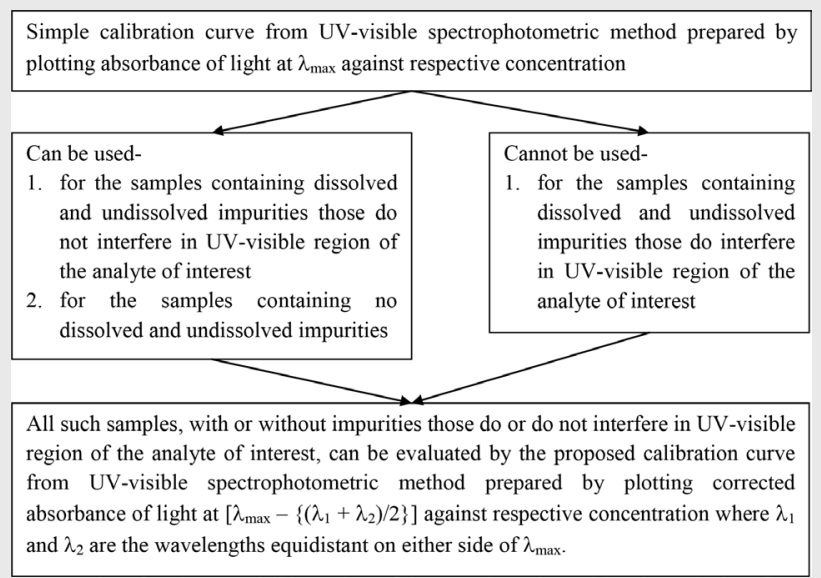

\section{SUMMARY}

The pharmaceutical formulations necessarily have some ingredients other than active pharmaceutical ingredient (API) for various purposes. Some of these ingredients also get released along with API during in vitro dissolution studies. While evaluating the dissolution samples by $\mathrm{UV}$-visible spectrophotometry, these ingredients might interfere with the API in UV-visible region. Also, some of the undissolved excipient impurities might be there in the dissolution samples. These insoluble impurities might also interfere. To avoid these interferences and to avoid filtration of the impurities from dissolution samples, a simple and sensitive ultraviolet spectrophotometric method for quantitative estimation of a model API, gliclazide, in presence of excipients is described to avoid false estimation due to presence of soluble or insoluble impurity. UV detections were performed at $226 \mathrm{~nm}, 221 \mathrm{~nm}$ and $231 \mathrm{~nm}$ and the calibration curve was plotted between resultant of absorbance of as per the equation [226 nm - $(221 \mathrm{~nm}+231 \mathrm{~nm}) / 2]$ and the concentration of the gliclazide. The calibration curve was found linear over $4-28 \mu \mathrm{g} / \mathrm{ml}$ concentration range with limit of detection and limit of quantification of $0.45 \mu \mathrm{g} / \mathrm{ml}$ and $1.36 \mu \mathrm{g} / \mathrm{ml}$, respectively. Percent relative standard deviations, representing precision, for pure as well as impure solutions were found to be within acceptable limits i.e. always less than 1.99 and 2.00 respectively for pure and impure solution respectively. The mean percent recovery, from the standard spiking method of accuracy, of $99.21 \%-102.04 \%$ and $102.06 \%-103.74 \%$ for pure and impure solutions respectively indicates that the developed method is accurate. Conclusively, the developed method was successfully applied for the quantitative estimation of gliclazide in pure as well as impure solutions and it was found that the drug analyte in both types of solutions can be detected from the same calibration curve accurately and precisely.

\section{About Authors}

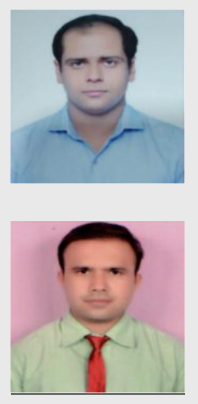

Dr. Neelkant Prasad, Ph. D. in Pharmaceutics (Pharmacy), has been engaged in teaching and research since September 2008. He is currently working with S G T College of Pharmacy, S G T University, Budhera, Gurugram, Haryana, India-122505. His research area focuses on liposomal drug delivery system, dissolution and bioavailability enhancement of poorly water soluble drugs, and analytical method development and validation.

Mr. Aditya Sharma, M. Pharm in Pharmaceutics (Gold Medalist) and pursuing Ph. D. in Pharmaceutical Sciences, has been engaged in teaching and research since last 2 years. He is currently working with School of Pharmaceutical Sciences, IFTM University, Lodhipur Rajput, Moradabad, Uttar Pradesh, INDIA-244102. He is a life member of Foundation for Health and Environment Research (FHER). His research area of interest covers solubility enhancement of poorly water soluble drugs, lipid based drug delivery systems and transdermal drug delivery systems.

Cite this article: Prasad N, Sharma A. Ultraviolet-visible Spectrophotometric Method for Estimation of Gliclazide in Presence of Excipients Interacting in UV-visible Region. Indian J of Pharmaceutical Education and Research. 2020;54(2s):s337-s343. 